\section{Long lasting}

neurocardiogenic reflex provoked by emotional trigger

\author{
DOROTA ZYŚKO • STANISLAW FURTAN • JACEK GAJEK • \\ ARKADIUSZ KAWKA
}

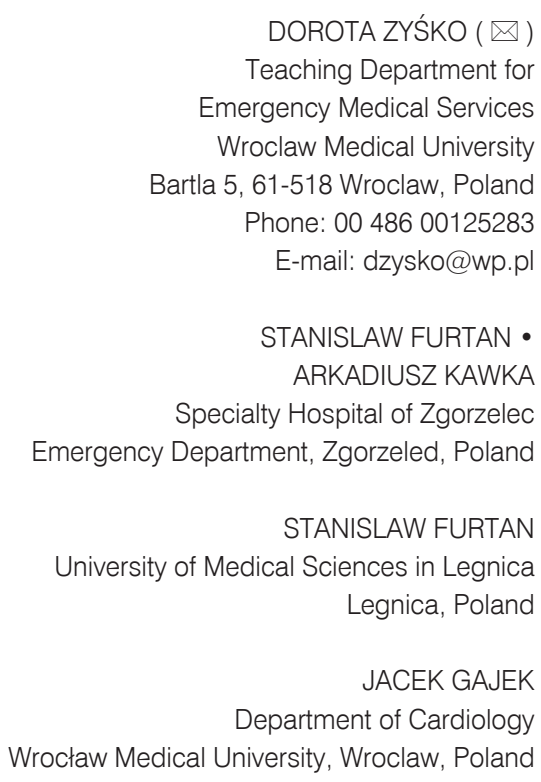

DOROTA ZYŚKO $(\bowtie)$

Teaching Department for Emergency Medical Services Wroclaw Medical University Bartla 5, 61-518 Wroclaw, Poland Phone: 0048600125283 E-mail: dzysko@wp.pl

STANISLAW FURTAN • ARKADIUSZ KAWKA

Specialty Hospital of Zgorzelec Emergency Department, Zgorzeled, Poland

STANISLAW FURTAN

University of Medical Sciences in Legnica Legnica, Poland

JACEK GAJEK

Department of Cardiology Wrocław Medical University, Wroclaw, Poland

\begin{abstract}
A 53-year-old man presented with a protracted presyncope and profound hypotension and bradycardia due to emotion related vasovagal reaction. Electrocardiogram obtained 20 minutes after the onset of presyncope revealed junctional rhythm at 38 beats per minute (bpm). After supination, clinical symptoms and hemodynamic disturbances immediately resolved. Careful cardiologic evaluation revealed significant stenosed coronary vessels. Maintaining the vertical position may be responsible for persistent bradycardia and hypotension after neurocardiogenic reflex provocation.
\end{abstract}

Key words: neurocardiogenic syncope, cardiovascular event.

\section{Introduction}

While there is much knowledge about ventricular pause and bradycardia time during tilt-induced or spontaneous vasovagal syncope with supination by table lowering or falling immediately after loss of consciousness, $(1,2)$ little is known what would happen if the upright posture was maintained.

The presented case sheds light on the problem of how long may the sequels of neurocardiogenic reflex last.

\section{Case report}

After witnessing a sudden loss of consciousness of an older woman in a church, a 53-year-old male experienced severe, long lasting presyncope mediated by emotion. Notwithstanding their presence, the man continued sitting because he was unwilling to lie on a bench in a public place, which resulted in sustained bradycardia and hypotension. The man was noticed by paramedics while he was sitting on the bench in the square, in front of the church. He was extraordinarily pale and was supported by a woman, his wife. Paramedics were there because of an emergency call to the collapsed older woman in the church. The wife said that her husband was frightened by the sudden fall of the older woman that happened next to him in the church. The man felt sick, turned pale and began to sweat. His wife helped him get out of the church into fresh air. Initially, the man was seated on the chair in the ambulance because the stretchers were taken by the older woman. His blood pressure was $80 / 40 \mathrm{mmHg}$. Electrocardiogram (ECG) revealed junctional rhythm at 38 beats per minute (bpm) (figure 1A). At that time, 20 minutes have passed since the emergency call. The places of man and woman were exchanged. After one minute, the sinus rhythm resolved (figure 1B), blood pressure increased to $90 / 50 \mathrm{~mm} \mathrm{Hg}$. The negative T waves in the lead II and III and aVF were observed. The patient had a history of presyncope due to blood phobia and arterial hypertension. He complained of exertional or resting burning chest pain lasting several minutes located retrosternally or on the right side of the chest. Patient denied any pain discomfort during the presyncopal event. Troponin levels immediately after coming to Emergency Department and 6 hours later were in the normal range. The negative T wave in leads II and aVF normalized and only a negative $T$ wave in the lead III persisted. The echocardiographic examination showed borderline left ventricular hypertrophy with 
normal ejection fraction at $60 \%$. Twenty four-hour ECG Holter monitoring did not reveal any significant rhythm disturbances. During exercise testing, the patient achieved less than $85 \%$ of his maximal predicted heart rate. Coronary computed tomography angiography was performed 2 months later and revealed right coronary artery amputation and $70 \%$ stenosis left anterior descending artery. Coronary angiography confirmed that diagnosis and stenting of the stenosis artery were performed.

\section{Discussion}

The onset of the event was undoubtedly related to emotional stress which provoked vasovagal reaction. The consciousness preservation was possible due to the junctional escape rhythm, and sitting position lengthened the duration of bradycardia and hypotension which was interrupted only by supination.

This was only possible due to the unusual circumstances of the event which could never be reproduced in an experiment because of ethical issues. No doctor would perform a tilt test in a patient with one coronary artery occluded and the other largely stenosed, and even if he did he would stop the neurocardiogenic reaction at once by placing the patient in a supine position.

Meanwhile, a lot of older patients with multiple comorbidities do not change their body position during neurocardiogenic reaction. Sometimes they are immobilized in a seated position and cannot move even if they feel very badly, or they lose consciousness in a seated position while the surrounding objects support them in a way which prevents them from slumping. In those cases, it is not possible to establish with certainty the origin of hypotension, bradycardia or even sudden cardiac death. Therefore, the presented case

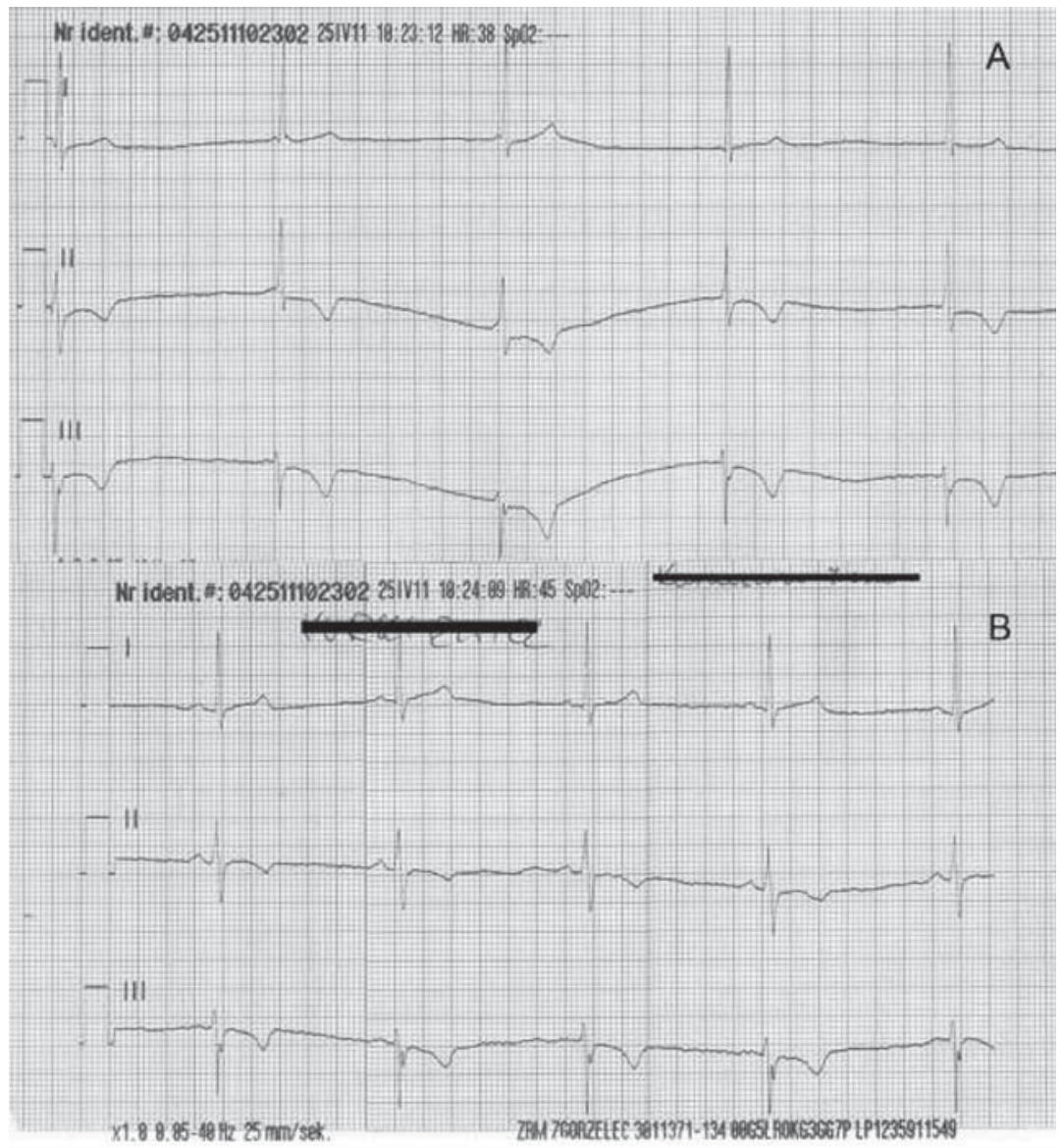

Figure 1. Upper panel (A) junctional rhythm, lower panel (B) sinus rhythm.

is of unique clinical importance, as the cause of event is unambiguous and the patient with significant coronary stenoses spent a lot of time in a supine position.

Previous observations indicate the possibility that longer tilt table lowering time is related to longer duration of either the loss of consciousness or ventricular pause. (2) Good prognosis of vasovagal syncope was proven in young people, but prolonged decrease of blood pressure in older patients may be responsible for cardiovascular events. (3-5) However, vasovagal presyncope evoked by prolonged orthostatic stress may resolve without changing the body position in surgeons and instrumentals during operation. (6)

During neurocardiogenic reaction, a relatively rapid junctional rhythm may suffice to maintain the blood pressure at the level required for consciousness preservation, (7) whereas atrio-ventricular block may be related to rapidly occurring presyncope. (8)

The presented case stresses the need for further studies on the possibility that the vasovagal syncope in certain circumstances (older patient being sitting supported by another person or an object from the environment) may cause cardiovascular event or death due to prolonged hypotension or asystole. 


\section{REFERENCES}

1. Brignole M, Sutton R, Wieling W, Lu SN, Erickson MK, Markowitz T, et al. Analysis of rhythm variation during spontaneous cardioinhibitory neurally-mediated syncope. Europace 2007;9:305-11.

2. Zyśko D, Gajek J, Kozluk E, Agrawal AK, Smereka J, Checiński I. The clinical relevance of the duration of loss of consciousness provoked by tilt testing. Acta Cardiol 2010;65:203-9.

3. Goolamali SI, Loh VL, Sopher M. The head-up tilt test - a cause of myocardial infarction. Europace 2004;6:548-51.

4. Gajek J, Zyśko D. Stroke and tilt table testing. Folia Cardiol 2002;9:583-6.

5. Zyśko D, Gajek J, Smereka J, Chęciński I, Ściborski R, Mazurek W. ST-elevation in a patient with vasovagal syncope Folia Cardiol 2006;13:530-3.

6. Rudnicki J, Zyśko D, Gajek J, Kuliczkowski W, Rosińczuk-Tonderys J, Zielińska D, et al. The Risk for Syncope and Presyncope During Surgery in Surgeons and Nurses. Pacing Clin Electrophysiol 2011;34:1486-91.

7. Zyśko D, Gajek J, Agrawal AK, Rudnicki J. The clinical relevance of a junctional rhythm during neurocardiogenic reaction provoked by tilt testing. Kardiol Pol 2012;70:148-55.

8. Gajek J, Zyśko D, Agrawal AK, Rudnicki J. Patients with atrioventricular block during tilt test-induced vasovagal syncope. Adv Clin Exp Med 2011;20:305-12. 